\title{
A Case of "en bloc" Excision of a Chest Wall Leiomyosarcoma and Closure of the Defect with Non-Cross-Linked Collagen Matrix (Egis ${ }^{\circledR}$ )
}

\author{
Marco Rastrelli ${ }^{a} \quad$ Saveria Tropea $^{a} \quad$ Romina Spina $^{a} \quad$ Alessandra Costa $^{a}$ \\ Roberto Stramare $^{b} \quad$ Simone Mocellin $^{a} \quad$ Maria Giuseppina Bonavina ${ }^{c}$ \\ Carlo Riccardo Rossi ${ }^{a}$

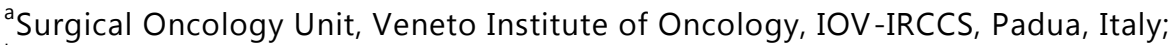 \\ ${ }^{b}$ Radiology Unit, University of Padua, Padua, Italy; ${ }^{\mathrm{C}}$ Medical Direction Unit, Veneto \\ Institute of Oncology, IOV-IRCCS, Padua, Italy
}

\section{Keywords}

Leiomyosarcoma · Thoracic wall · Acellular dermis · Guided tissue regeneration

\begin{abstract}
Sarcomas arising from the chest wall account for less than $20 \%$ of all soft tissue sarcomas, and at this site, primitive tumors are the most frequent to occur. Leiomyosarcoma is a malignant smooth muscle tumor and the best outcomes are achieved with wide surgical excision. Although advancements have been made in treatment protocols, leiomyosarcoma remains one of the more difficult soft tissue sarcoma to treat. Currently, general local control is obtained with surgical treatment with wide negative margins. We describe the case of a 50year-old man who underwent a chest wall resection involving a wide portion of the pectoralis major and minor muscle, the serratus and part of the second, third and fourth ribs of the left side. The full-thickness chest wall defect of $10 \times 8 \mathrm{~cm}$ was closed using a non-cross-linked acellular dermal matrix $\left(\right.$ Egis $\left.^{\circledR}\right)$ placed in two layers, beneath the rib plane and over it. A successful repair was achieved with no incisional herniation and with complete tissue regenera-
\end{abstract}


tion, allowing natural respiratory movements. No complications were observed in the postoperative course. Biological non-cross-linked matrix, derived from porcine dermis, behaves like a scaffold supporting tissue regeneration; it can be successfully used as an alternative to synthetic mesh for chest wall reconstruction.

\section{Introduction}

Leiomyosarcoma is a malignant neoplasm showing pure smooth muscle differentiation [1]. It accounts for $5-10 \%$ of all soft tissue sarcomas [2, 3]. The treatment of choice is surgical resection with wide negative margins [4]. Depending on the primary site there may be a different prognosis and biological characteristics; in fact, an aggressive clinical course and a high rate of systemic relapse after curative resection in the abdominal primary site are observed [2]. When surgical margins are close, especially in high-grade sarcomas, preoperative or postoperative radiation therapy constitutes an important additional treatment, while the primary role of chemotherapy is in the treatment of metastatic disease [5, 6].

Leiomyosarcoma may arise in any anatomical location, but more than $50 \%$ of cases are located in retroperitoneal/intra-abdominal and pelvic sites, and predominantly arise from larger blood vessels [6]. The formation of leiomyosarcomas in other sites is less common, accounting for $10-15 \%$ of limb sarcomas [7]. A study on 343 patients affected by trunk wall sarcoma, published by the French sarcoma group in 2009, estimates that the most frequent tumor types were undifferentiated sarcomas (27.7\%) followed by myogenic sarcomas (rhabdomyosarcomas and leiomyosarcomas; 19.2\%) [3].

After a wide local chest excision, prosthetic replacement is necessary to protect the organs in the thoracic cavity. The success of different reconstruction materials depends on both the surgeon's experience and the material. Traditionally, synthetic mesh and a muscular flap are used to cover the chest wall defect, but the risk of secondary infection of the wound and the prosthesis as well as mesh extrusion still remains [8]. Nevertheless, considering infection as the most common postoperative complication in thoracic surgery, whether from initial wound contamination and adequate debridement or secondary infection $[9,10]$, biologic matrices should be chosen for their higher biocompatibility, strength, host tissue incorporation, and infection resistance [11].

These collagen-based materials have been utilized sparingly due to the high costs, but have provided adequate strength and stability over time with good outcomes, such that they can be considered as useful materials for soft tissue reconstruction [12]. Nowadays, the more affordable price of some new brands gives the opportunity to enlarge their use in different indications.

This report presents the first thoracic reconstruction using Egis ${ }^{\circledR}$ (Decomed, Venice, Italy), a porcine acellular dermal matrix, after leiomyosarcoma excision.

\section{Case Report}

A 50-year-old man reported in March 2015 the onset of a swelling on the left side of the chest, below the armpit, with an increasing mass, being painful during palpation. After examination with MRI in October 2015, the formation of $48 \times 47 \times 35 \mathrm{~mm}$ had a liquid density appearance at the level of the soft tissues of the chest wall, suspected to be a sarcoma. An ultrasound examination 1 month later showed an inhomogeneous hypoechoic solid for- 


\section{Case Reports in Oncology}

mation, polylobed, apparently pedunculated with moderate intralesional vascularity. The CT scan confirmed the presence of a solid mass over the left chest wall, suspected to be a primitive sarcoma.

The patient underwent neoadjuvant chemotherapy and radiation therapy, completed in March 2016. At the restaging CT scan, an increase in the solid mass to the left hemithorax was observed $(64 \times 42 \times 50 \mathrm{~mm})$, placed between the chest wall, the pectoralis minor muscle, and cranial portion of the serratus anterior muscle, against which no apparent adipose cleavage planes were detected (Fig. 1a); the lesion had infiltrated the third intercostal space and appeared in close continuity with neighboring ribs which had no erosive cortical alterations.

In April 2016, we performed a surgical resection of the tumor by combined removal of a portion of the second, third and fourth left ribs with a 2-cm margin from the mass; partial resection of the pectoralis major and minor muscle was performed, with simultaneous removal of the axillary adipose tissue and the lymph nodes beneath the pectoralis minor. Laterally, resection of a portion of the latissimus dorsi muscle was carried out with isolation and section of the spinal and long thoracic nerves which were embedded in the mass. The $10 \times 8 \mathrm{~cm}$ defect (Fig. 2a) was covered with the biologic non-cross-linked matrix Egis ${ }^{\circledR}$ (Decomed). The membrane used (30 $\times 21 \mathrm{~cm}$ large and $1.5 \mathrm{~mm}$ thick) was dry and without chemical preservatives, and it did not require any washing treatment; it takes only 5 min for hydration in saline solution at room temperature. It was placed in two layers, fixed with an interrupted absorbable suture $2 / 0$, the first one beneath the plane of the sectioned ribs, the second above the previous one (Fig. $2 \mathrm{~b}, \mathrm{c}$ ). The skin incision was closed by planes, after the placement of pleural drainage and careful hemostasis. Antibiotic treatment was administrated for about 10 days after the surgery.

Pathological examination of the surgical specimen confirmed the presence of leiomyosarcoma with extensive areas of necrosis and posttreatment sclerohyalinosis, a nonmetastatic lymph node and skin, muscle fragments, and rib segments not infiltrated by the tumor.

The postoperative course had no complications. The CT scan analysis 4 months later shows the presence of the membrane with no evidence of bulging or herniation (Fig. 1b).

\section{Discussion}

Primary chest wall tumors are uncommon and more than half of them are malignant; of these, soft tissue tumors account for roughly $50 \%$. The most common site of involvement for all chest wall lesions is the rib cage $[1,2,5]$. The present case was diagnosed as a leiomyosarcoma.

In the treatment of primary leiomyosarcomas, appropriate surgery is needed [13]. Extensive resection with a sufficient margin $(2-3 \mathrm{~cm})$ is considered as a first-line therapy [5]. We here reported an "en bloc" chest wall resection with 2 -cm disease-free margins and the removal of the lateral portion of 3 ribs. As the defect involved less than 4 consecutive ribs, it did not require skeletal stabilization. However, the tissue sacrifice was such that it did not allow an effective coverage of the defect with a flap; this led us to replace the defective tissue with a prosthetic material. Historically, synthetic materials have often been used for surgical soft tissue reconstruction; their choice is based on convenience, reliability and ease of application, but it should be noted that they are also susceptible to physical tissue erosion and encapsulation process, and must therefore be removed if they become infected [10-12]. 
Indeed, approximately $6 \%$ of patients treated with polypropylene mesh experience secondary infection of the prosthesis, which typically required its removal $[8,11]$.

The ideal strategy to reconstruct the tissue would be to completely regenerate the anatomical structure and function of the defective tissue [14]. The advent of multiple tissuederived products in the 1990s introduced the possibility of using a collagen membrane as a scaffold to provide an optimal healing environment. Biologic matrices, obtained mostly from human or animal dermis, are ideal templates for tissue repair and regeneration, preventing foreign body reaction associated with the use of synthetic materials [11].

The combined use of both synthetic and biologic prosthesis is frequently reported for the reconstruction of large defects, in order to guarantee mechanical resistance and structural durability. Azoury et al. [10] proposed a double-layer technique with inlay positioning of a biologic membrane, an acellular dermal matrix acting as a "neo-pleura" in intimate contact with lung parenchyma, and onlay synthetic mesh placement. However, this procedure has the same risks of postoperative infection associated with synthetic mesh; therefore, a complete biological reconstruction should be preferable, which it might yield superior longterm results [11].

Despite the great advantages of biologic matrices compared to synthetic ones, their biggest limitation is the high cost, and this has considerably restricted the indications [15]. In the last few years, some new brands offer biological matrices at a more affordable price. This allows extending the indication also in cases without evidence of an active infected field, but with the possible risk of future infections.

In this case, we consider improving the procedure by Azoury et al. [10] by dividing a $30 \times 20 \mathrm{~cm}$ porcine acellular dermal matrix (Egis ${ }^{\circledR}$, Decomed) in 2 parts and placing it in 2 layers, beneath the plane of the sectioned ribs, in close contact with the parenchyma, and above it, replacing the function of the synthetic mesh. Since the product is acellular, it does not stimulate any immunologic reactions; the collagen structure is progressively repopulated by new blood vessels and cells, turning it into self-tissue and providing an effective repair (Fig. 1b).

This case report suggest that the acellular dermal matrix Egis ${ }^{\circledR}$ is a suitable alternative to synthetic meshes in chest wall reconstruction, especially in fields at risk of infection like in immunodeficient patients, in patients who underwent radiotherapy, as well as in diabetics. Since this procedure is available at an affordable price, it may be more widely used.

\section{Statement of Ethics}

According to the Declaration of Helsinki, informed consent was required and signed by the patient before the submission of the paper.

\section{Disclosure Statement}

No funding was provided for the preparation of the manuscript. The authors have no relevant conflicts of interest or financial disclosures. 
Rastrelli et al: A Case of "en bloc" Excision of a Chest Wall Leiomyosarcoma and Closure of the Defect with Non-Cross-Linked Collagen Matrix $\left(\right.$ Egis $^{\circledR}$ )

\section{References}

1 Fletcher CDM, Bridge JA, Hogendoorn PCW, Mertens F (eds): WHO Classification of Tumours of Soft Tissue and Bone. Pathology and Genetics of Tumours of Soft Tissue and Bone, ed 4. Lyon, IARC Press, 2013.

2 Kim HJ, Cho YJ, Kim SH, Rha SY, Ahn JB, Yang WI, Lee YH, Suh JS, Roh JK, Kim KS, Choi YD, Shin KH, Kim HS: Leiomyosarcoma: investigation of prognostic factors for risk-stratification model. Int J Clin Oncol 2015;20:1226-1232.

-3 Salas S, Bui B, Stoeckle E, Terrier P, Ranchere-Vince D, Collin F, Leroux A, Guillou L, Michels JJ, Trassard M, Valo I, Robin YM, Marques B, Brouste V, Coindre JM: Soft tissue sarcomas of the trunk wall (STSTW): a study of 343 patients from the French Sarcoma Group (FSG) database. Ann Oncol 2009;20:1127-1135.

4 Gladish GW, Sabloff BM, Munden RF, Truong MT, Erasmus JJ, Chasen MH: Primary thoracic sarcomas. Radiographics 2002;22:621-637.

5 Rastrelli M, Tropea S, Basso U, Roma A, Maruzzo M, Rossi CR: Soft tissue limb and trunk sarcomas: diagnosis, treatment and follow-up. Anticancer Res 2014;34:5251-5262.

6 'Singer S, Tap WP, Crago AM, O'Sullivan B: Soft tissue sarcoma; in DeVita VT, Lawrence TS, Rosenberg SA (eds): Cancer: Principles and Practice of Oncology. Philadelphia, Lippincott, Williams \& Wilkins, 2014, pp 1253-1292.

7 Massi D, Beltrami G, Mela MM, Pertici M, Capanna R, Franchi A: Prognostic factors in soft tissue leiomyosarcoma of the extremities: a retrospective analysis of 42 cases. Eur J Surg Oncol 2004;30:565572.

8 Deschamps C, Tirnaksiz BM, Darbandi R, Trastek VF, Allen MS, Miller DL, Arnold PG, Pairolero PC: Early and long-term results of prosthetic chest wall reconstruction. J Thorac Cardiovasc Surg 1999;117:588591.

-9 Hazel K, Weyant MJ: Chest wall resection and reconstruction: management of complications. Thorac Surg Clin 2015;25:517-521.

10 Azoury SC, Grimm JC, Tuffaha SH, Broyles JM, Fischer AC, Yang SC, Tufaro AP: Chest wall reconstruction evolution over a decade and experience with a novel technique for complex defects. Ann Plast Surg 2016;76:231-237.

11 Weigmann B, Zardo P, Dickgreber N, Langer F, Fegbeutel C, Haverich A: Biological materials in chest wall reconstruction: initial experience with the Peri-Guard repair patch. Eur J Cardiothorac Surg 2010;37:602-605.

-12 George RS, Kostopanagiotou K, Papagiannopoulos K: The expanded role of extracellular matrix patch in malignant and non-malignant chest wall reconstruction in thoracic surgery. Interact Cardiovasc Thorac Surg 2014;18:335-339.

13 Ayabe T, Tomita M, Mori H, Chosa E, Nakamura K: A resection of the giant first left rib tumor and chest wall reconstruction by transmanubrial osteomuscular sparing approach. Open J Thorac Surg 2015;5:35-42.

14 Hodde J, Hiles M: Constructive soft tissue remodelling with a biologic extracellular matrix graft: overview and review of the clinical literature. Acta Chir Belg 2007;107:641-647.

15 Barua A, Catton JA, Socci L, Raurell A, Malik M, Internullo E, Martin-Ucar AE: Initial experience with the use of biological implants for soft tissue and chest wall reconstruction in thoracic surgery. Ann Thorac Surg 2012;94:1701-1705. 


\section{Case Reports in Oncology}

\begin{tabular}{l|l}
\hline Case Rep Oncol 2016;9:655-660 \\
\hline DOI: 10.1159/000452147 & $\begin{array}{l}\text { @ 2016 The Author(s). Published by S. Karger AG, Basel } \\
\text { www.karger.com/cro }\end{array}$ \\
\hline
\end{tabular}

Rastrelli et al.: A Case of "en bloc" Excision of a Chest Wall Leiomyosarcoma and Closure of the Defect with Non-Cross-Linked Collagen Matrix (Egis ${ }^{\circledR}$ )
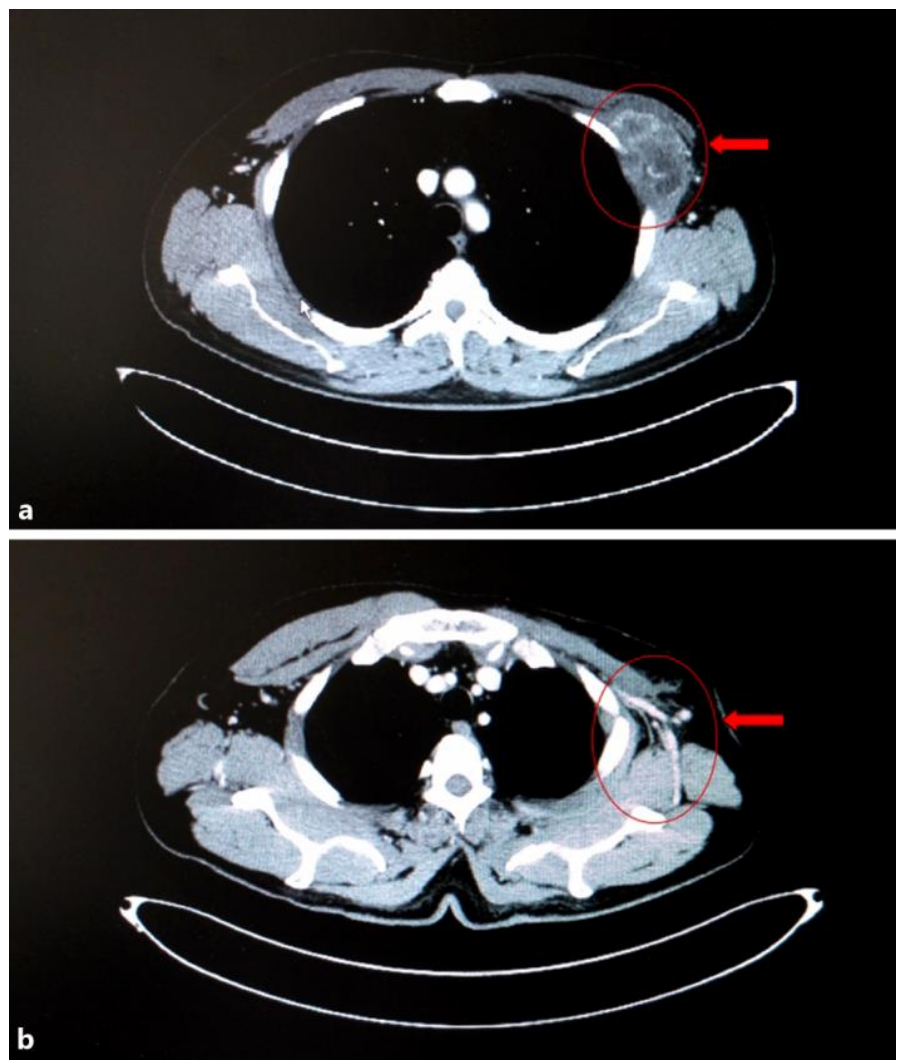

Fig. 1. a Preoperative CT scan confirms the presence of a solid mass (arrow) on the left chest wall. b Postoperative CT scan shows the presence of the matrix with no tumor recurrence or lung bulging (arrow).
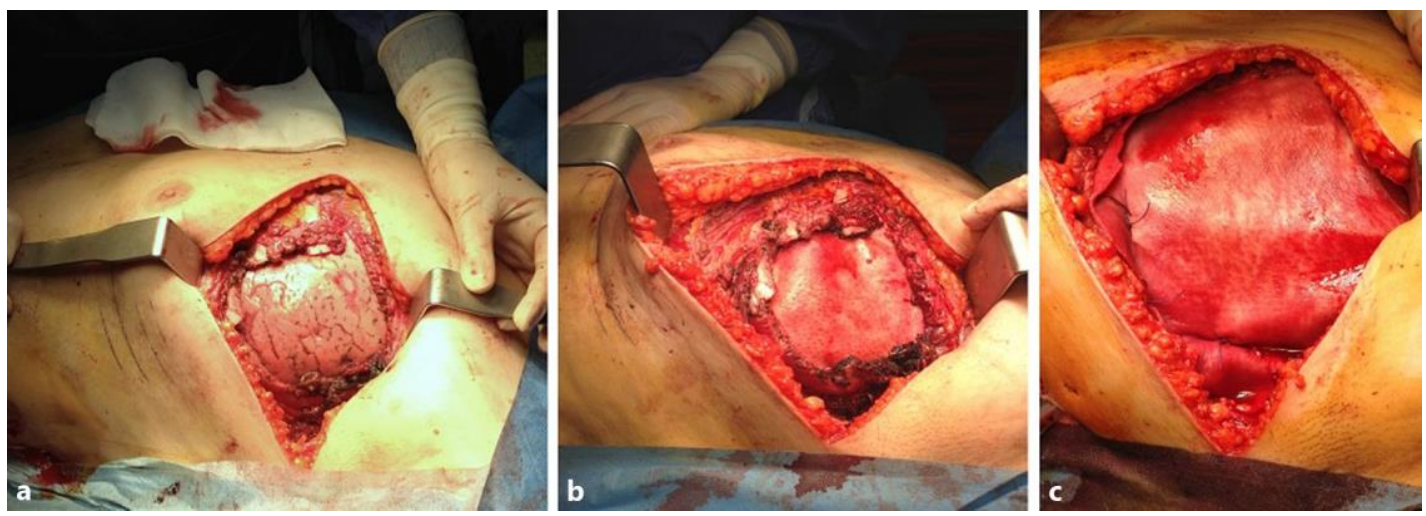

Fig. 2. a $10 \times 8 \mathrm{~cm}$ full-thickness defect, with resection of a portion of the second, third and fourth rib. Lung structure in the foreground. $\mathbf{b}$ Closure of the defective tissue with the non-cross-linked acellular dermal matrix Egis ${ }^{\circledR}$ placed in 2 layers. Focus on the inner layer, fixed with absorbable suture beneath the plane of the sectioned ribs. c Magnification of the second layer of Egis ${ }^{\circledR}$, fixed above the first one. 